\title{
Microstructure Refinement by Low-Temperature Ausforming in an Fe-Based Metastable High-Entropy Alloy
}

\author{
Motomichi Koyama 1,2,*, Takeaki Gondo ${ }^{3}$ and Kaneaki Tsuzaki ${ }^{1,2,3,4}$ \\ 1 Institute for Materials Research, Katahira Campus, Tohoku University, 2-1-1 Katahira, Aoba-ku, \\ Sendai 980-8577, Japan; TSUZAKI.Kaneaki@nims.go.jp \\ 2 Elements Strategy Initiative for Structural Materials (ESISM), Kyoto University, Yoshida-honmachi, Sakyo-ku, \\ Kyoto 606-8501, Japan \\ 3 Department of Mechanical Engineering, Faculty of Engineering, Ito Campus, Kyushu University, \\ 744 Motooka, Nishi-ku, Fukuoka 819-0395, Japan; gondo.takeaki.287@s.kyushu-u.ac.jp \\ 4 Research Center for Structural Materials, National Institute for Materials Science, 1-2-1 Sengen, \\ Tsukuba 305-0047, Japan \\ * Correspondence: koyama@imr.tohoku.ac.jp; Tel.: +81-022-215-2061
}

Citation: Koyama, M.; Gondo, T.; Tsuzaki, K. Microstructure Refinement by Low-Temperature Ausforming in an Fe-Based Metastable High-Entropy Alloy. Metals 2021, 11, 742. https:// doi.org/10.3390/met11050742

Academic Editor: Babak Shalchi Amirkhiz

Received: 1 April 2021

Accepted: 27 April 2021

Published: 30 April 2021

Publisher's Note: MDPI stays neutral with regard to jurisdictional claims in published maps and institutional affiliations.

Copyright: (C) 2021 by the authors. Licensee MDPI, Basel, Switzerland. This article is an open access article distributed under the terms and conditions of the Creative Commons Attribution (CC BY) license (https:/ / creativecommons.org/licenses/by/ $4.0 /)$.

\begin{abstract}
The effects of ausforming in an Fe30Mn10Cr10Co high-entropy alloy on the microstructure, hardness, and plastic anisotropy were investigated. The alloy showed a dual-phase microstructure consisting of face-centered cubic (FCC) austenite and hexagonal close-packed (HCP) martensite in the as-solution-treated condition, and the finish temperature for the reverse transformation was below $200{ }^{\circ} \mathrm{C}$. Therefore, low-temperature ausforming at $200{ }^{\circ} \mathrm{C}$ was achieved, which resulted in microstructure refinement and significantly increased the hardness. Furthermore, plasticity anisotropy, a common problem in HCP structures, was suppressed by the ausforming treatment. This, in turn, reduced the scatter of the hardness.
\end{abstract}

Keywords: ausforming; high-entropy alloy; martensite; microstructure refinement; plastic anisotropy

\section{Introduction}

Increasing the strength of structural materials has been a long-standing issue in material engineering. The strength of Fe-based alloys has been improved through various thermal and mechanical processes. The variety of thermal and mechanical processes used for steels is due to the occurrence of martensitic transformation during cooling. Specifically, martensite in steels is hard, which results in extraordinary strengthening. When ductility is required, the combination of martensite and other phases realizes highly deformable and high-tensile strength steels (e.g., dual-phase steel [1]). Furthermore, ausforming, wherein the steel is deformed at the austenite (face-centered cubic (FCC) phase) state before the martensitic transformation, enables a drastic improvement in the strength of martensite due to the high dislocation density and microstructure refinement of martensite [2].

Ausforming treatment has primarily been utilized for body-centered cubic (BCC) martensite as the martensite morphology can be lath, which results in high strength, as mentioned above. In addition to the morphological viewpoint, the following conditions are preferred for maximizing the strengthening effect of ausforming. (1) The start temperature for thermally induced martensitic transformation $\left(M_{s}\right)$ must be higher than room temperature. (2) The start and finish temperatures for the reverse transformation $\left(A_{s}\right.$ and $\left.A_{f}\right)$ must be low to suppress the occurrence of recovery and recrystallization during the heat treatment. (3) The stacking fault energy of the FCC phase must be low at the ausforming temperature to suppress dynamic recovery. (4) Precipitation, which can deteriorate ductility (such as $\sigma$ phase), must be suppressed during heat treatment. In this regard, the thermal hysteresis of the FCC - HCP forward and reverse transformations is generally small, which enables satisfying conditions (1) and (2). Furthermore, when the HCP martensite forms, the stacking fault energy is always low, which satisfies condition (3). In addition, most of alloy 
compositions that show FCC-HCP martensitic transformation do not show significant precipitation at a low temperature (e.g., around $200^{\circ} \mathrm{C}$ ) - that is, the four conditions can be more easily satisfied in HCP martensite than in BCC martensite. Therefore, attempts have been made to develop ausforming treatments for HCP martensite [3,4].

In this context, a metastable Fe30Mn10Cr10Co (at.\%) high-entropy alloy (HEA) containing a considerable amount of solute atoms has recently been noted as a next generation high-strength alloy [5-7]. The metastable HEA shows thermal- and deformation-induced FCC-HCP martensitic transformation, which simultaneously improve the yield strength and tensile ductility via microstructure refinement and transformation-induced plasticity [8]. Herein, we consider the thermally induced HCP martensite, which results in an FCC/HCP dual microstructure in the as-solution-treated condition. Ausforming treatment in the metastable HEA is expected to result in further microstructure refinement and associated strengthening.

Notably, there exist certain disadvantages of HCP martensite. (1) HCP martensite can act as a crack initiation site $[9,10]$. (2) The plasticity of the HCP structure is anisotropic compared with that of the BCC and FCC structures. According to previous studies [11,12], metastable HEAs exhibit nonbasal plane slip more easily compared to conventional HCP alloys. The exceptional activity of nonbasal plane slip improves ductility and relaxes plasticity anisotropy. Hence, ausforming treatment in the metastable HEA may provide a new strategy to create a high-strength ductile alloy. In this paper, as the first step, we present the microstructure refinement by ausforming and the associated changes in hardness and plasticity anisotropy.

\section{Materials and Methods}

A $5 \mathrm{~kg}$ ingot of Fe30Mn10Cr10Co alloy was prepared by vacuum induction melting. The chemical composition is listed in Table 1 . The ingot was hot-rolled at $1000{ }^{\circ} \mathrm{C}$. The hot-rolled bar was solution-treated at $900{ }^{\circ} \mathrm{C}$ for $30 \mathrm{~min}$ and subsequently water-quenched. As mentioned in the Introduction, the as-solution-treated microstructure consisted of the FCC/HCP dual phase microstructure (Figure 1). The phase map was obtained by electron backscatter diffraction (EBSD) measurement, and the measurement conditions are explained later in this section. The $\mathrm{M}_{\mathrm{s}}, \mathrm{A}_{\mathrm{s}}$, and $\mathrm{A}_{\mathrm{f}}$ temperatures were determined to be 55 , 133 , and $152{ }^{\circ} \mathrm{C}$, respectively, as shown in Figure 2, by differential scanning calorimetry (DSC, Shimadzu) at heating and cooling rates of $20^{\circ} \mathrm{C} \mathrm{min}-1$. The $\mathrm{M}_{\mathrm{s}}$ temperature was measured by heating from 21 (room temperature) to $200{ }^{\circ} \mathrm{C}$ and subsequent cooling to $-40{ }^{\circ} \mathrm{C}$. The $\mathrm{A}_{\mathrm{s}}$ and $\mathrm{A}_{\mathrm{f}}$ temperatures were measured by subsequent heating from -40 to $200^{\circ} \mathrm{C}$. The specific critical temperatures for the transformations were determined as the intersection points of two tangential lines on the DSC curves, as shown in Figure 2.

Table 1. Chemical composition of the HEA used (mass $\%$ ).

\begin{tabular}{ccccccccccc}
\hline $\mathbf{C}$ & $\mathbf{M n}$ & $\mathbf{P}$ & $\mathbf{S}$ & $\mathbf{N}$ & $\mathbf{O}$ & $\mathbf{A l}$ & $\mathbf{C r}$ & $\mathbf{C o}$ & $\mathbf{N i}$ & $\mathbf{F e}$ \\
\hline 0.009 & 29.84 & 0.004 & 0.007 & 0.010 & 0.013 & 0.002 & 9.55 & 10.69 & $<0.01$ & Bal. \\
\hline
\end{tabular}

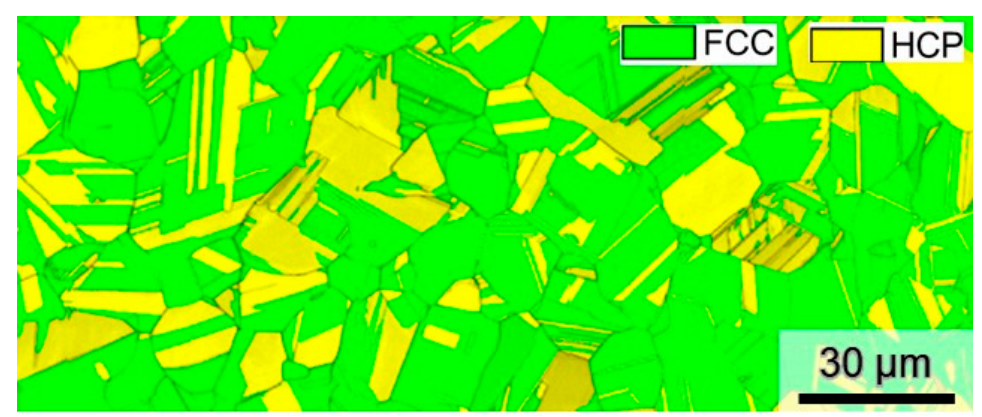

Figure 1. Phase map showing an overview of the as-solution-treated microstructure. 


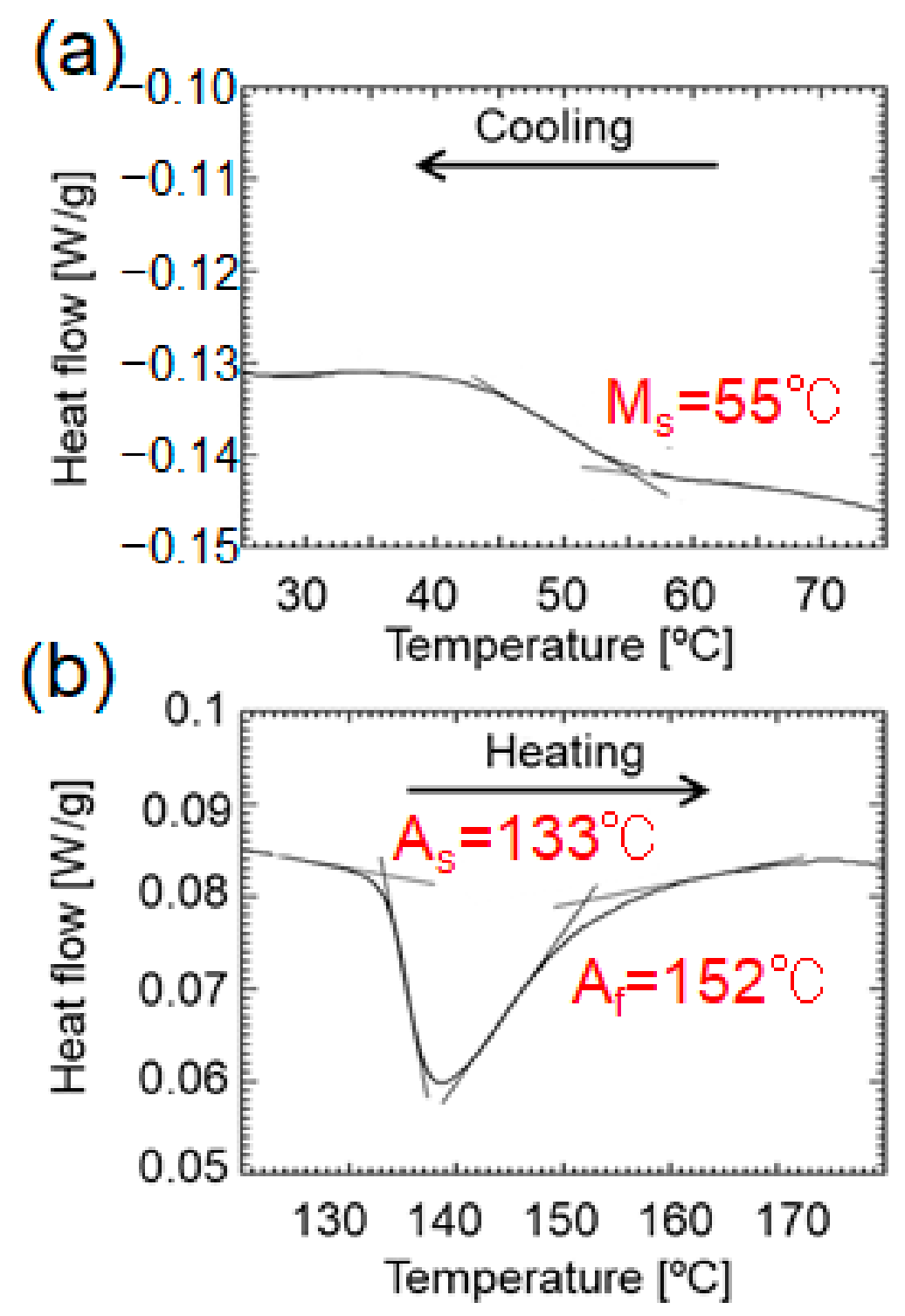

Figure 2. DSC curves of (a) cooling and (b) heating processes.

A tensile specimen with the geometry shown in Figure 3a was taken from the solutiontreated bar by spark machining. The specimen geometry was selected to fix our experimental setup for the high-temperature tensile testing with a thermostatic chamber. The tensile test was carried out by using an Instron type tensile machine (Shimadzu, Autograph, maximum load $=10 \mathrm{KN}$ ). The specimen was deformed until fracture at an initial strain rate of $10^{-4} \mathrm{~s}^{-1}$ and temperature of $200{ }^{\circ} \mathrm{C}$, which was higher than the $\mathrm{A}_{\mathrm{f}}$ temperature. The stress-strain curve obtained from the HEA tensile specimen showed approximately $30 \%$ uniform elongation (Figure $3 \mathrm{~b}$ ). The fractured specimen contained deformed and undeformed portions, as shown schematically in Figure 4. Specifically, the grip section and uniformly deformed region highlighted in red in the schematics of the specimens show $0 \%$ and approximately $30 \%$ strains, respectively. Therefore, the portions of the undeformed and uniformly deformed regions of the fractured specimen underwent annealing at $200{ }^{\circ} \mathrm{C}$ without deformation (low-temperature annealing) and ausforming at $200{ }^{\circ} \mathrm{C}$, respectively. As the deformation temperature of $200^{\circ} \mathrm{C}$ is much lower than the recrystallization temperature of FCC-based HEAs, which is above $500{ }^{\circ} \mathrm{C}[13,14]$, the present ausforming treatment can be considered as a low-temperature ausforming treatment. 


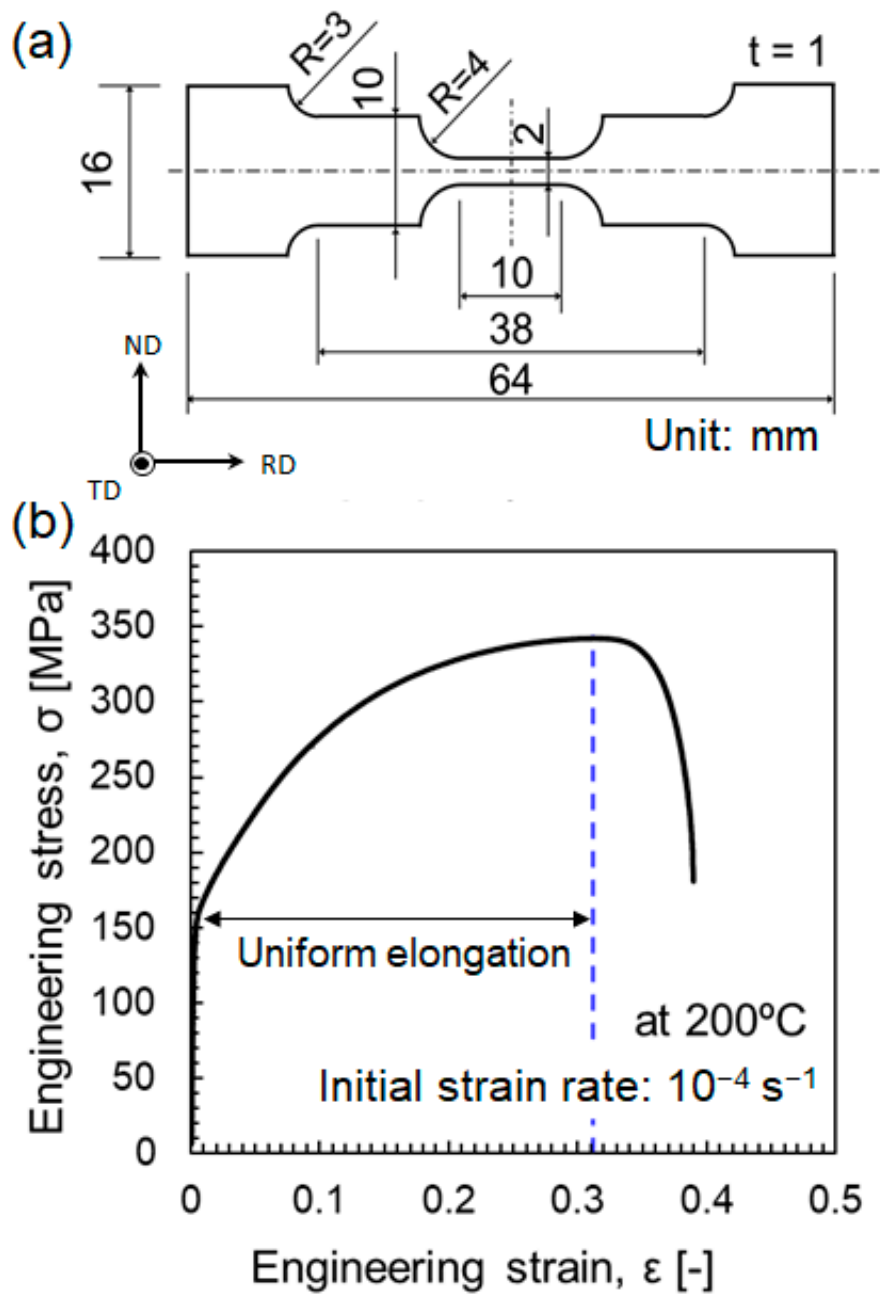

Figure 3. (a) Tensile specimen geometry and (b) engineering stress-strain curve of the specimen.
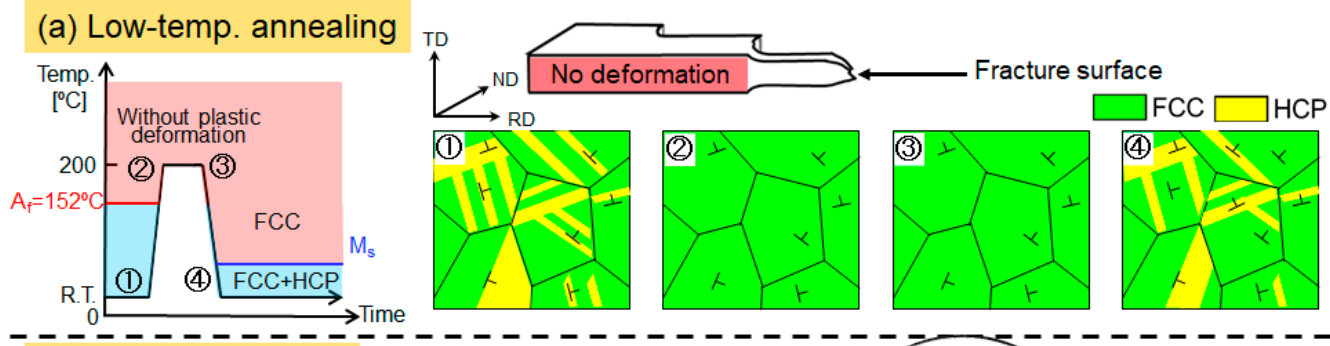

(b) Ausforming
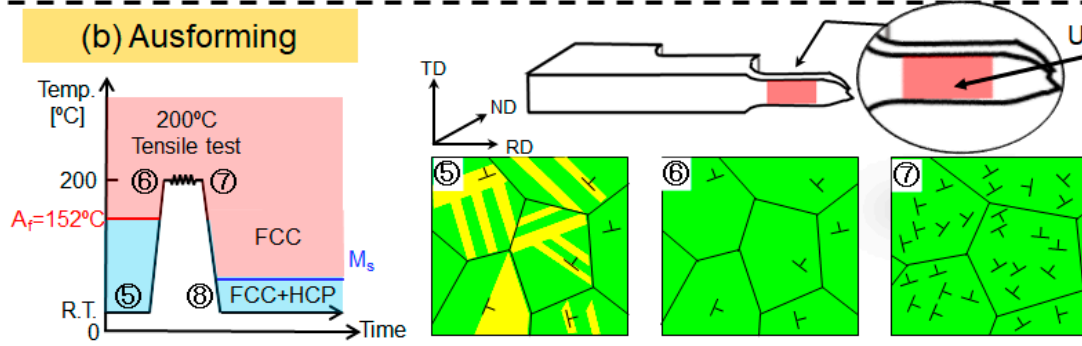

Uniformly deformed

Figure 4. Schematic diagrams of the heat treatment history and expected microstructures for (a) low-temperature annealing and (b) ausforming. Highlighted regions in the schematic illustration of the fractured specimens indicate the targets of the present observations.

In this study, the hardness and microstructure of the as-solution-treated, lowtemperature-annealed, and ausformed specimens were characterized by Vickers hardness testing, EBSD analysis, and electron channeling contrast imaging (ECCI) using 
a field emission scanning electron microscope (Zeiss, Merlin). The specimens for the hardness tests and microstructure observations were mechanically polished by emery papers, diamond suspensions, and colloidal silica with a particle size of $60 \mathrm{~nm}$. The Vickers hardness tests were conducted twelve times for each condition at a maximum load of $0.3 \mathrm{kgf}$ with a holding time of $30 \mathrm{~s}$. The minimum and maximum values were excluded to calculate the average values of hardness. The EBSD measurements were performed at an acceleration voltage of $20 \mathrm{kV}$ with a beam step size of $50 \mathrm{~nm}$, and ECCI was performed at an acceleration voltage of $30 \mathrm{kV}$.

\section{Results and Discussion}

Figure $5 a_{1}-c_{1}$ show the microstructures of the as-solution-treated, low-temperatureannealed, and ausformed specimens. Ausforming resulted in microstructure refinement, which was achieved by the formation of fine HCP martensite (Figure $5 a_{2}-c_{2}$ ). The HCP martensite exhibited multiple crystallographic orientations with a specific orientation relationship: $\{111\}_{\mathrm{FCC}} / /(0002)_{\mathrm{HCP}}\left(\right.$ Figure $\left.5 \mathrm{a}_{3}-\mathrm{C}_{3}\right)$.
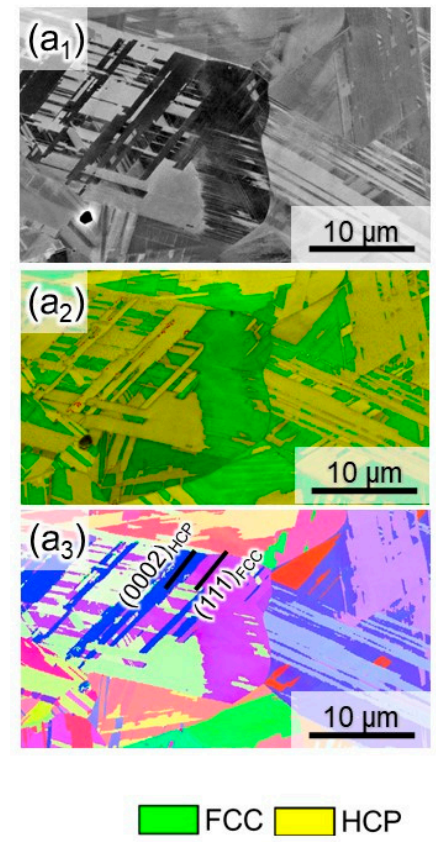
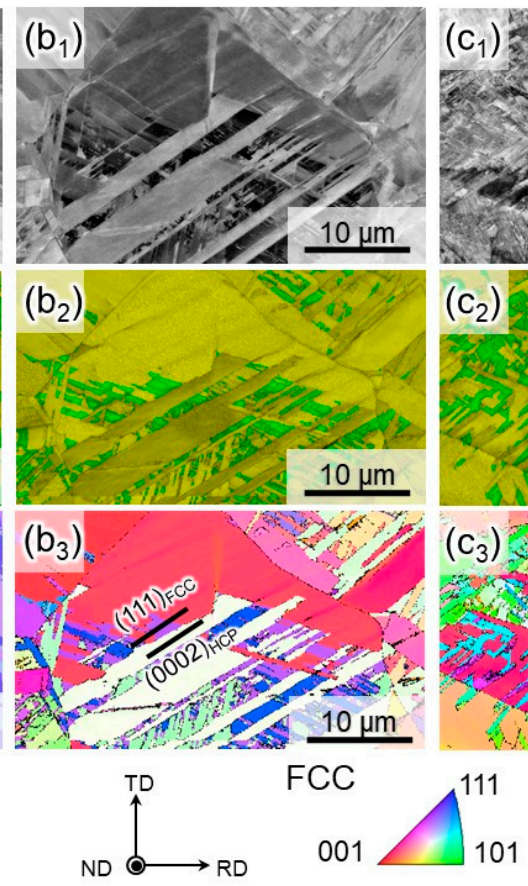
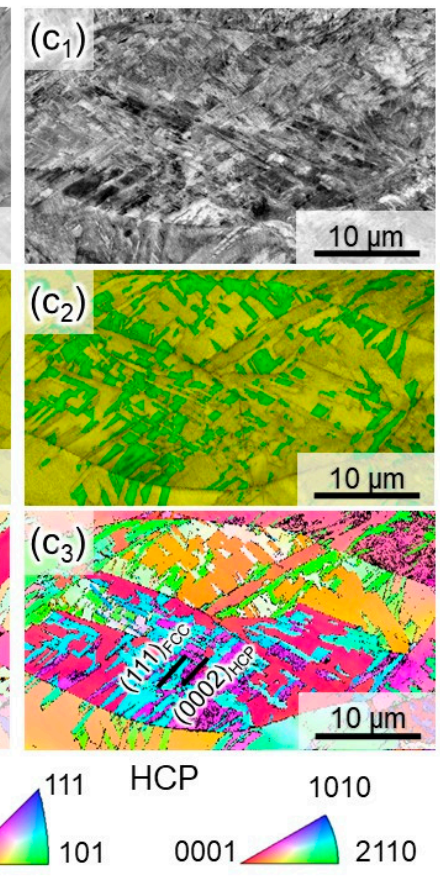

Figure 5. ECCI images, phase map, and ND-IPF maps of the $\left(\mathbf{a}_{1}-\mathbf{a}_{3}\right)$ as-solution-treated, $\left(\mathbf{b}_{1}-\mathbf{b}_{3}\right)$ low-temperature-annealed, and $\left(c_{1}-c_{3}\right)$ ausformed specimens. The black lines in $\left(c_{1}-c_{3}\right)$ indicate examples of traces along the $(111)_{\text {FCC }}$ or $(0002)_{\text {HCP }}$ planes.

Figure 6 shows the ECCI images displaying the dislocation microstructure of the specimens. The microstructures of the as-solution-treated and low-temperature-annealed specimens had low dislocation density and homogeneous contrast gradient (Figure 6a,b). In contrast, the ausformed specimen showed a distinct dislocation microstructure evolution and heterogeneous contrast distribution (Figure $6 \mathrm{c}$ ). The contrast heterogeneity was observed in both the FCC austenite and HCP martensite. Furthermore, in the ausformed microstructure, thin HCP martensite plates or stacking faults were observed, and their tips were located at the FCC/HCP interface or dislocation substructure of the austenite region, as shown in Figure 7. These results indicate the following: (1) a large residual stress associated with lattice distortion exists; (2) the FCC/HCP interface and dislocation substructure act as barriers against growth of thermally induced HCP martensite in the present metastable HEA. Hence, the residual stress and dislocation substructure caused by ausforming prevent the growth of HCP martensite and instead increase the probability of martensite nucleation, which results in microstructure refinement. 

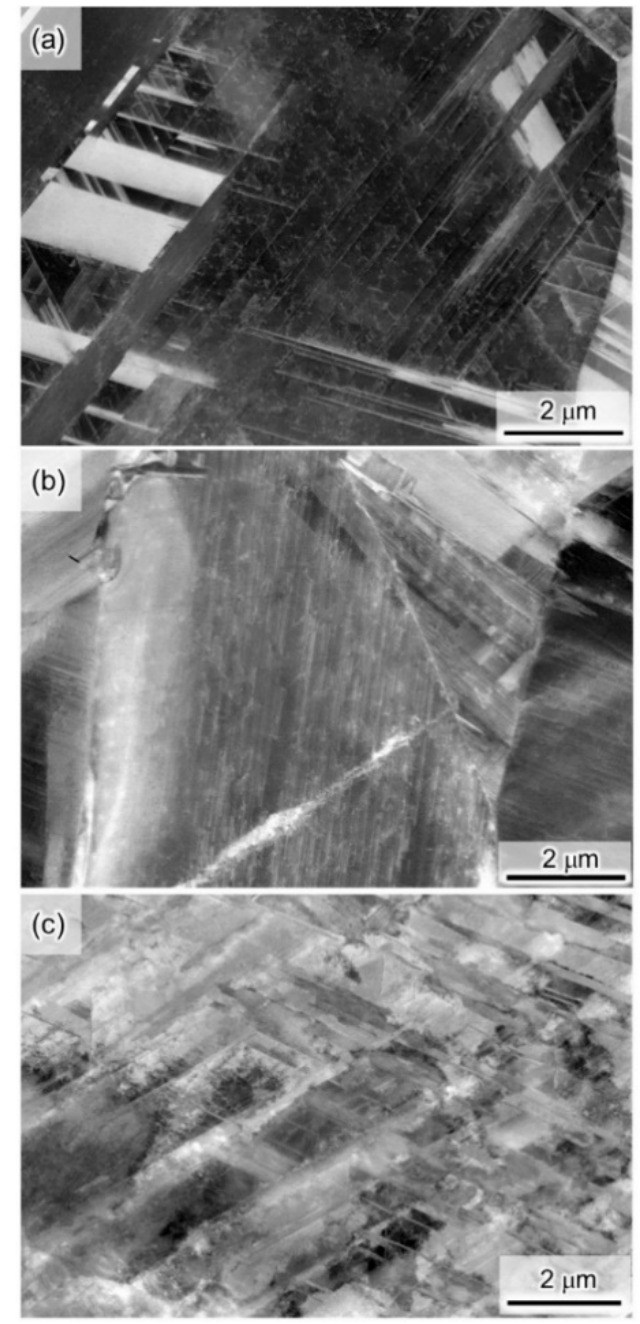

Figure 6. High-magnification ECCI images of (a) the as-solution-treated, (b) the low-temperatureannealed, and (c) the ausformed specimens.

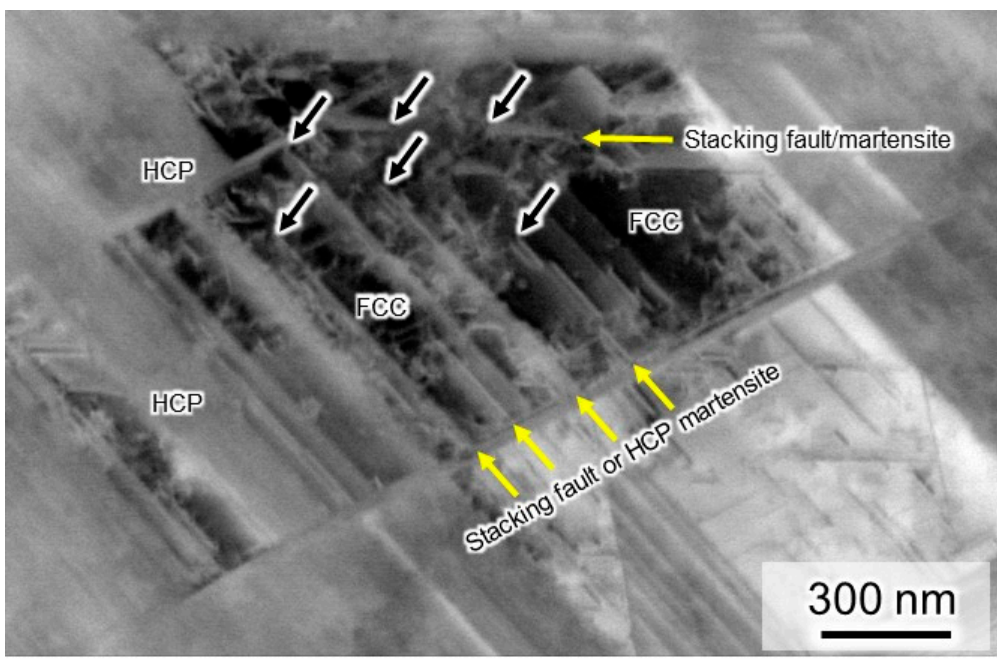

Figure 7. Further magnified ECCI image of the ausformed specimen. The black arrows indicate tips of the stacking faults or HCP martensite plates.

Table 2 lists the results of the hardness tests. The ausformed specimen showed a remarkable increase in hardness, which was attributed to the dislocation hardening and microstructure refinement, as shown in Figures 5-7. Interestingly, the ausforming 
treatment decreased the scatter of the hardness. In addition, the surface relief formations by indentation in the ausformed specimen were relatively homogeneous compared to those in the other two specimens (Figure 8a-c). The homogeneous surface relief formation in the ausformed specimen was commonly observed in all the indented regions. Since the shape and topography of indentation marks have a correspondence with anisotropic plastic deformation [15] and associated dislocation behavior [16], the present results indicate that plasticity anisotropy of the HCP structure was reduced by the ausforming treatment. A plausible reason for the reduced anisotropy is the introduction of lattice distortion. The activity of the nonbasal plane slip, which is crucial for overcoming the anisotropy problem, is associated with the c/a ratio of the HCP martensite lattice [12]. The lattice distortion, which was observed as electron channeling contrast heterogeneity within each grain shown in Figures $6 \mathrm{c}$ and 7, implies that the lattice constant of the HCP martensite locally changed owing to the presence of the dislocation substructure that evolved during ausforming. The local change in the lattice constant may assist the activation of the nonbasal plane slip. In addition, the microstructure refinement achieved by the formation of thermally induced HCP martensite with different crystallographic orientations is another factor that can reduce the plasticity anisotropy and the associated scatter of hardness. As mentioned in the introduction section, when HCP martensite is used for strengthening, plastic anisotropy and associated crack initiation are problematic. In this context, the present study demonstrated that the ausforming treatment in the metastable HEA simultaneously improves the strength and suppresses plasticity anisotropy.

Table 2. Vickers hardness test results and their standard deviations.

\begin{tabular}{cccc}
\hline & As-Solution-Treated & Low-Temp. Annealed & Ausformed \\
\hline Hardness & $191 \pm 12 \mathrm{HV}$ & $173 \pm 11 \mathrm{HV}$ & $252 \pm 5 \mathrm{HV}$ \\
\hline
\end{tabular}
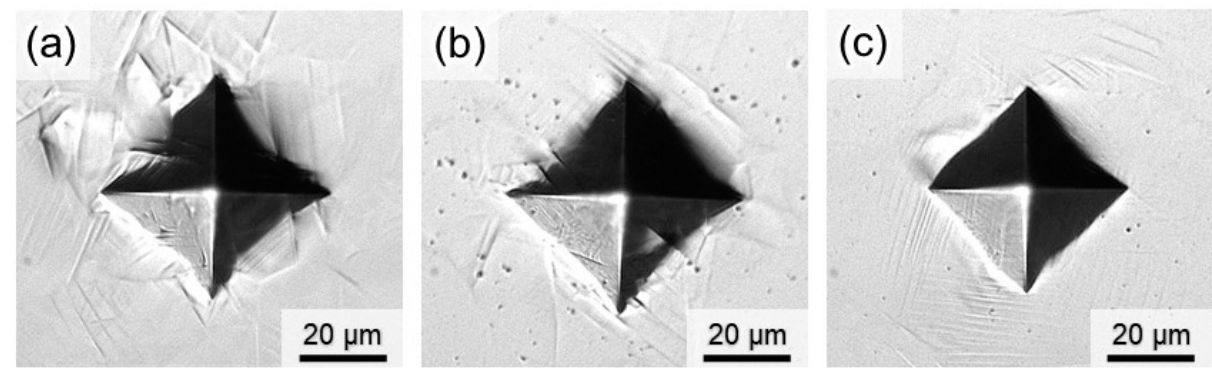

Figure 8. Indents after the Vickers hardness tests in (a) as-solution-treated, (b) low-temperatureannealed, and (c) ausformed specimens.

\section{Conclusions}

In the present study, an ausforming treatment was performed for the metastable HEA that showed thermally induced FCC-HCP martensitic transformation. The treatment resulted in microstructure refinement and a high dislocation density, which improved the strength. In terms of microstructure evolution, dislocation substructures, which evolved during ausforming, prevented subsequent growth of thermally induced HCP martensite, which caused formation of numerous fine HCP martensites with multiple crystallographic orientations. In addition, the scatter of hardness and plastic anisotropy during indentation were reduced by the ausforming treatment, which indicates that the ausforming treatment suppressed plasticity anisotropy of the microstructure containing HCP martensite. The suppression of plasticity anisotropy is perhaps due to the presence of residual stress and microstructure refinement associated with the thermally induced FCC-HCP martensitic transformation.

Author Contributions: Conceptualization, K.T. and M.K.; methodology, K.T.; validation, M.K.; formal analysis, T.G.; investigation, T.G.; resources, K.T. and M.K.; data curation, K.T. and M.K.; 
writing—original draft preparation, M.K.; writing—review and editing, K.T.; visualization, T.G. and M.K.; funding acquisition, K.T. and M.K. All authors have read and agreed to the published version of the manuscript.

Funding: This research was funded by JSPS KAKENHI (JP16H06365; JP20H02457; JP21K04702) and Elements Strategy Initiative for Structural Materials (ESISM) of Ministry of Education, Culture, Sports, Science and Technology (MEXT) Japan (JPMXP0112101000).

Institutional Review Board Statement: Not applicable.

Informed Consent Statement: Not applicable.

Data Availability Statement: The data presented in this study are available on request from the corresponding author. The data are not publicly available as the data also form part of an ongoing study.

Acknowledgments: T.G. thanks Mayumi Sakamoto and Yoshihiro Fukushima for their assistance in the hardness testing.

Conflicts of Interest: The authors declare no conflict of interest.

\section{References}

1. Tasan, C.C.; Diehl, M.; Yan, D.; Bechotold, M.; Roters, M.; Schemmann, L.; Zheng, C.; Peranio, N.; Ponge, D.; Koyama, M.; et al. An Overview of Dual-Phase Steels: Advances in Microstructure-Orientated Processing and Micromechanically Guided Design. Ann. Rev. Mater. Res. 2015, 45, 391-431. [CrossRef]

2. Tamura, I. Some Fundamental Steps in Thermomechanical Processing of Steels. ISIJ Int. 1987, 27, 763-779. [CrossRef]

3. Tsuzaki, K.; Fukasaku, S.-I.; Tomota, Y.; Maki, T. Effect of Prior Deformation of Austenite on the $\gamma \rightarrow \varepsilon$ Martensitic Transformation in Fe-Mn Alloys. Mater. Trans. JIM 1991, 32, 222-228. [CrossRef]

4. Wang, D.; Liu, D.; Dong, Z.; Liu, W.; Chen, J. Improvement of Shape Memory Effect by Ausforming in Fe-28Mn-6Si-5Cr Alloy. Mater. Sci. Eng. A 2001, 315, 174-179. [CrossRef]

5. Li, Z.; Pradeep, K.G.; Deng, Y.; Raabe, D.; Tasan, C.C. Metastable High-Entropy Dual-Phase Alloys Overcome the StrengthDuctility Trade-Off. Nature 2016, 534, 227-230. [CrossRef]

6. Niendorf, T.; Wegener, T.; Li, Z.; Raabe, D. Unexpected Cyclic Stress-Strain Response of Dual-Phase High-Entropy Alloys Induced by Partial Reversibility of Deformation. Scr. Mater. 2018, 143, 63-67. [CrossRef]

7. Koyama, M.; Tasan, C.C.; Tsuzaki, K. Overview of Metastability and Compositional Complexity Effects for Hydrogen-Resistant Iron Alloys: Inverse Austenite Stability Effects. Eng. Fract. Mech. 2019, 214, 123-133. [CrossRef]

8. Li, Z.; Tasan, C.C.; Pradeep, K.G.; Raabe, D. A TRIP-Assisted Dual-Phase High-Entropy Alloy: Grain Size and Phase Fraction Effects on Deformation Behavior. Acta Mater. 2017, 131, 323-335. [CrossRef]

9. Takaki, S.; Furuya, T.; Tokunaga, Y. Effect of Si and Al Additions on the Low Temperature Toughness and Fracture Mode of Fe-27Mn Alloys. ISIJ Int. 1990, 30, 632-638. [CrossRef]

10. Koyama, M.; Kaneko, T.; Sawaguchi, T.; Tsuzaki, K. Microstructural Damage Evolution and Arrest in Binary Fe-High-Mn Alloys with Different Deformation Temperatures. Int. J. Fract. 2018, 213, 193-206. [CrossRef]

11. Eguchi, T.; Koyama, M.; Fukushima, Y.; Tasan, C.C.; Tsuzaki, K. Fatigue Crack Growth Behavior and Associated Microstructure in a Metastable High-Entropy Alloy. Procedia Struct. Integr. 2018, 13, 831-836. [CrossRef]

12. Bu, Y.; Li, Z.; Liu, J.; Wang, H.; Raabe, D.; Yang, W. Nonbasal Slip Systems Enable a Strong and Ductile Hexagonal-Close-Packed High-Entropy Phase. Phys. Rev. Lett. 2019, 122, 075502. [CrossRef] [PubMed]

13. Otto, F.; Hanold, N.L.; George, E.P. Microstructural Evolution after Thermomechanical Processing in an Equiatomic, Single-Phase CoCrFeMnNi High-Entropy Alloy with Special Focus on Twin Boundaries. Intermetallics 2014, 54, 39-48. [CrossRef]

14. Bhattacharjee, P.P.; Sathiaraj, G.D.; Zaid, M.; Gatti, J.R.; Lee, C.; Tsai, C.-W. Microstructure and Texture Evolution during Annealing of Equiatomic CoCrFeMnNi High-Entropy Alloy. J. Alloys Compd. 2014, 587, 544-552. [CrossRef]

15. Zambaldi, C.; Raabe, D. Plastic Anisotropy of $\gamma$-TiAl revealed by axisymmetric indentation. Acta Mater. 2010, 58, 3516-3530. [CrossRef]

16. Hua, D.; Xia, Q.; Wang, W.; Zhou, Q.; Li, S.; Qian, D.; Shi, J.; Wang, H. CoCrNi medium entropy alloy under nanoindentation. Int. J. Plast. 2021, 142, 102997. [CrossRef] 